\title{
The Effect of Thesis Statement on Persuasiveness and Logicality
}

\author{
Wenqing Zhang \\ Special Police of China, Beijing 102211, China. \\ Email: dengdengel@163.com
}

Abstract: "Thesis statement is the main idea of your essay, the central point your essay supports. ${ }^{,[1]}$ It can be regarded as the root of your article, so its significance is inevitable. Writing an effective thesis statement and developing it clearly and logically are necessities for an excellent essay. Where to introduce the thesis statement and how to develop it also affect the logicality and persuasiveness of the essay, so this paper will focus on the thesis statements of five essays and analyze where they are introduced and how they develop in the articles respectively in order to find their influence on the logicality and persuasiveness of the essay.

Keywords: Thesis Statement; Persuasiveness; Logicality; Writing Technique

\section{Introduction}

Different authors have different writing techniques through which the articles can express different purpose and show different effects. Where to put forward the thesis statement and how to develop it are also in fact one technique the writer uses to show the main idea and create a kind of effect, especially effect on persuasiveness and logicality. This paper will focus on the location and development of thesis statements in five articles to analyze persuasiveness and logicality presented.

\section{The location of thesis statement and its effect on logicality}

As usual, the thesis statement would be put up with by author in the introductory paragraph, that means usually in first paragraph. Like in the essay How to do well on a job interview, the author Glenda Davis gives us the thesis statement in the introductory part of the essay, to be specifically, in third paragraph. And in Propaganda Techniques in Today's Advertising, the thesis statement lies in the first three paragraph. The paper Why frequency can no longer be ignored in ELT also represents it in introductory part. So for these three article, we can see that their logicality for the papers is very clear. That means the readers can catch their purposes of writing these papers quickly and clearly. But there are also subtle differences between these three articles on the location of thesis statement. Like the How to do well on a job interview, after reading the first for the description of the progress of job interview and the explanation of the interview game, the readers naturally are leaded into the main topic of the essay---"here are guidelines to help you play the interview game to win., ${ }^{,[2]}$ Then the readers understand immediately what will talk about later in the paper and follow the presentment of the guidelines step by step until finishing the whole one. Therefore, in these progresses, the readers can form a structure of the paper in mind easily and even do not need to review it. However, several guidelines are not so proper for some people who can not be convinced, which erodes the persuasiveness of the paper no matter how clear it demonstrates its thesis statement. The Here's to Your Health is same. Then we talk about Propaganda Techniques in Today's Advertising in which the thesis statement is demonstrated in same ways like the above one and specified in fourth paragraph. However, the difference between the two is that Ann McClintock (the author of second

Copyright $@ 2020$ Wenqing Zhang

doi: $10.18282 /$ le.v9i7.1476

This is an open-access article distributed under the terms of the Creative Commons Attribution Non-Commercial License

(http://creativecommons.org/licenses/by-nc/4.0/), which permits unrestricted non-commercial use, distribution, and reproduction in any medium, provided the original work is properly cited. 
article) shows a hidden thesis statement in the first three paragraphs which is the final purpose for her to write the essay, so this kind of arrangement just creates a kind of sense of uncertainty. That means for readers it is not easy to grasp the logicality of the essay. The obvious and implicit demonstration of the two statements respectively will endow them a sense of disconnection of the paper. Readers will subtly feel the loss of logicality of the article. However, for the supporting examples are very persuasive, the readers would feel the paper is more convinced than the first one. Then for Why frequency can no longer be ignored in ELT written by Geoffrey Leech, its thesis statement lies in the first paragraph of introduction part and is presented obviously in one sentence. Then Leech shows us the brief structure of the essay and some knowledge of the Frequency. This kind of location can help readers to grasp the contents they are eager to know quickly. They would not have to read the last part of introduction, if they knew the background knowledge well. Therefore, this kind of way to introduce thesis statement before background information in introductory part can give reader a chance to accept or reject it. What is different from the above two is that some readers this time may not be leaded by author and not follow the logical development of whole passage. Though for this group of readers the logicality for the essay is not so clear in mind compared with the first two, they can grasp the essence of the paper easily and quickly.

Then we talk about the last essay---Smash Thy Neighbor which does not mention the thesis statement in introductory part, which gives a sense of unclear logicality, even none logicality. This essay seems like a type of narration, though it aims to argue that the football is a sort of colorful morality play. John McMurtry starts the article with his own experience in football as introductory part, then illustrating the war-like football competition with practical examples and again his own experience. Then almost end of the article, he shows the thesis statement and gives several supports. So this sort of confused arrangement and later emergence of thesis statement makes the essay nonlogical particularly. The readers just feel confused about the title and content at beginning, especially when the title is also not clear one. Though at last, they find the certain idea in the article, they will feel disconnection between the former part and last part, especially for this one which gives a large amount of description for the features of football competition. Consequently, putting thesis statement in the middle of article is really an adventure no matter what the former part is the supports of the thesis or not. The sort of disconnection would wreck seriously the logicality of the whole paper.

\section{The method of developing the thesis statement and its effect on persuasiveness}

As we know, the persuasiveness of the essay replies on the good development and supports of the thesis statement whatever the statement is less acceptable or not. Like the first two essay--- Propaganda Techniques in Today's Advertising and Here's to Your Health, both discussion links to the bad effect of adverting. In first essay, when talking about the advertising's promotion of the harmful myth about drinking, the author Joan Dunayer develops the topic with the method of one myth, one rejection of myth, in summary four myths and rejections. This kind of technique of development strengthen the convincingness of the essay. The reader may not be convinced totally by just the myths in advertisement in drinking, for they may hold that there is no wrong with the idea conveyed by the ads that alcohol is the magic ingredient for social success if they do not know the situation well. But after the author gives the retort of these ideas and tells the readers the true situation in which the friendship built based on alcohol is unstable, they can be convinced and accept the myth well, so the persuasiveness of the essay would be enhanced. Compared with this article, the second one develops the obvious thesis by listing the techniques and the hidden one by explanation and practical examples with directivity. The author does not give explicit resorts and shows it in these ways. This method gives the readers the opportunity to choose to be persuaded or not. That means the readers have more autonomy in deciding whether the reasons are convincing or not, compared with the first article in which the readers are more probably leaded by the author's resorts. As a result, the persuasiveness is not so strong in the second one---Propaganda Techniques in Today's Advertising. Following its route, the convincingness in How to Do Well on a Job Interview is weaker. The article develops the thesis with some kinds of advice of guidelines to help you play the interview game to win. Therefore, for this kind of advice, some may come from the author's investigation, some from his own experience, or just from his opinion. For readers, they may meet different interviewing situations in different companies which have different requirements from expected employers, so some advice is not suitable for them and not convincing too, 
like the advice about how to answer the question like what your weakness is to say I am a perfectionist. Accordingly, developing the thesis by the deflected subjective ideas will erode the persuasiveness of the essay.

After that, we talk about another essay different from the first two---Why frequency can no longer be ignored in ELT? Like the first part has mentioned, because the essay is inclined into the theoretic type, so the development of its thesis also combines with many theories of Frequency and their development in chronological sequence. This development gives the readers the clear time line and undeniable theory framework, thus sometimes has strong persuasiveness, especially when the thesis in fact is a kind of tendency in time like this one in which frequency technique is more applied in current English teaching. And last essay Smash Thy Neighbor has also strong persuasiveness though less compared with the above one, for the author uses his own experience as reasons to develop the thesis, which gives the readers no room to have a resort particularly for who is not the attendant in the field. Though the author puts up with the thesis very later in the essay, but the former foreshadowing of his experience gives the strong proof to his following reasons for the thesis, which strengthens the persuasiveness of the essay typically.

\section{Conclusion}

In conclusion, we can see that the different locations of thesis statements will influence the logicality of the article deeply. To be more specific, thesis statement appears in the introductory part but after the introduction of background will give the readers a good structure of the essay in mind. On the contrary, the thesis introducing in the middle or at last of the essay can confuse the authors who may feel difficult to grasp the structure of the article. What's more, when presenting in the introductory part but before the introduction of background, the essay would help readers to catch the essence quickly. And how to develop the thesis statement will influence the persuasiveness of the essay, like developing it with practical examples and its resort to what has been represented will enhance the persuasiveness, by contrast, with practical example but no resort will weaken it. Also developing the thesis with the author's own opinion will be weaker, however, with the author's own experience will be stronger. Then if the article tends to be one theoretical one and is written for professional purpose and its thesis is developed by professional knowledge with practical examples, the persuasiveness is totally strong. The influence of the two aspects of thesis statement on logicality and persuasiveness is undeniable and divided into different levels. The author should consider well what kind of logicality and persuasiveness they want to show to readers, then make a decision about where to put forward the thesis statement and how to develop it well.

\section{References}

1. Kirszner G. Larurio G. and Mandell R. Stephen, The Wadsworth Handbook. Beijing: Remin University of China, $2008,41$.

2. McClintock Ann, "Propaganda Techniques in Today's Advertising”, In College Writing skills with Readings, edited by Langen John, 651-655. Beijing: Foreign Language Teaching and Research Press, 2007.

3. Leech Geoffrey, "Why frequency can no longer be ignored in ELT", In College Writing skills with Readings, edited by Langen John, 3-20. Beijing: Foreign Language Teaching and Research Press, 2007.

4. Dunayer Joan, Here's to Your Health, In College Writing skills with Readings, edited by Langen John, 667-669. Beijing: Foreign Language Teaching and Research Press, 2007.

5. Davis Glenda, "How to Do Well on a Job Interview," In College Writing skills with Readings, edited by Langen John, 233-235. Beijing: Foreign Language Teaching and Research Press, 2007.

6. McMurtry John, "Smash Thy Neighbor", In College Writing skills with Readings, edited by Langen John, 608-612. Beijing: Foreign Language Teaching and Research Press, 2007. 